effected when the oil was given, although the latter was not absolutely necessary.

The doses used were: for cattle from half-an-ounce to I ounce, for calves I drachm to 2 drachms, and for lambs from i 5 minims to I drachm.

That these doses can be increased if desired the following observations, which were made in order to test the toxic property, will show.

Mr Scott gave a dog, 42 pounds weight, nine months old, 2 drachms of solid extract of Baylahuen after fasting the animal for twenty-four hours (this solid extract was prepared in order that it might be readily administered in the form of pill or ball, and was about four times as strong as the fluid extract). Two hours later 3 drachms more were given, and after another two hours a further dose of 3 drachms; the animal thus got $\mathrm{I}$ ounce within about four hours. The only symptoms produced were those of mild alcoholic intoxication, viz., sleepiness, dulness, and unsteadiness of gait, but the animal seemed quite bright and responded when spoken to. Two hours after the administration of each dose all effects appeared to have passed off, and there was nothing abnormal noticeable.

In using the fluid extract, I gave a dog, weighing i 2 pounds, I ounce mixed with I ounce of water; another dog weighing 35 pounds got 2 ounces mixed with 2 ounces of water, and a full-grown sheep got 4 ounces mixed with 4 ounces of water; at no time afterwards was any untoward or objectionable symptoms noticed, the animals taking their food regularly and appearing bright and lively.

In summing up the results there certainly seems excellent reason for placing Extract of Baylahuen amongst the therapeutic agents at present made use of as stomachics and astringents in the treatment of diarrhœea, especially of young animals; its particular advantage over opium and some of the other agents at present in use being that it is free from all nauseating or after-depressant effects, and does not appear to possess any toxic property when given in anything like reasonable doses.

\title{
A CASE OF GLANDULAR ENLARGEMENT IN A MARE, SIMULATING TUBERCULOSIS.
}

\section{By Sydney L. Stephens, M.R.C.V.S., Wadebridge, Cornwall.}

THE subject was an aged grey Shire mare, the property of a gentleman farmer, who had bought her in the early part of last summer as a mare in foal and in good condition, from a stud farm in the Midlands. On arrival at her new home, some three months later, she was in very poor condition, but seemed hearty, and worked well on a liberal diet.

On 3oth November, whilst at work, the mare was seized with violent colic, went to ground gasping for breath, and was with difficulty got into her loose-box. She was quietened by the administration of a colic drench, followed two hours later by a purgative ball. The heart sounds were weak, and undue pressure within the thorax evident. By and December a hard swelling of the size and shape of a bun had appeared bilaterally on the third and fourth cervical 
vertebræ, and there was also some subcutaneous effusion under the body. Diuretics and tonics prescribed. Tuberculosis or melanosis feared. On 5th December the mare, on being exercised for the first time since the attack, repeated the colicky performance of 30 th November. On the evening of 15 th December she was inoculated with tuberculin, and her temperature was regularly recorded until 7 A.M. on the 17 th. There was no reaction. On 18 th and $22 n d$ December exercise was again attempted, and with the same results as before. Her appetite remained unimpaired during the whole period, until she was found clead on the morning of the I 7 th January. There was no evidence of any death struggle.

The autopsy next day revealed an emaciated carcase, with former swellings almost disappeared, but a soft enlargement inside the off thigh, involving the mammary gland, and containing a serous fluid. There was no foetus present. The abdominal cavity contained about I $\frac{1}{2}$ gallons of serous fluid. Peritoneum much discoloured. Mesenteric blood-vessels engorged. Mesenteric glands greatly enlarged and softened. Mucous membrane of stomach and intestines apparently healthy. Spleen enlarged, but free from tumours. Liver darker than normal, and very friable. Kidneys normal. Thorax contained about $2 \frac{1}{2}$ gallons of serous fluid. Lungs pleural and pericardium discoloured. Heart hypertrophied. Tracheal glands tremendously enlarged.

Portions of the viscera were forwarded to Professor M'Fadyean, who reported that the enlarged mesenteric and tracheal lymphatic glands had a structure which indicated a condition of hyperplasia, the bulk of the new tissue being composed of uni-nuclear lymphocytes. There was no evidence of caseation or other degeneration, and no giant cells were present. Sections and scrapings from the diseased glands were stained for tubercle bacilli, but with a negative result.

\section{CYSTIC CALCULI IN A BITCH.}

\section{By Henry Gray, M.R.C.V.S., London.}

SUBJECT.-An aged (about ten years) small fox-terrier bitch, very fat. For some time she had been noticed to have a great difficulty in passing urine, the act appearing to cause her pain. The last two days before I was consulted she made several attempts to pass urine, which was bloody and in small quantity; there was also occasional vomiting, drowsiness, loss of spirit, a desire for sleep, and no inclination for exercise. On 2oth March she was brought to me, because the owner thought she had been injured. On examination I found strings of bloody fibrin hanging from the inferior commissure of the vulva. The vagina was constricted, as it generally is in old bitches which have never borne young, and on separating the lips of the vulva a large quantity of bloody urine escaped. About $\mathrm{I} \frac{1}{2}$ in. from the vulva I detected a calculus the size of a large marble in the urethra, and on manipulating it with the two index fingers-one in the rectum and the other in the vagina-seven small calculi, each about the size of a tare and of a triangular form, shot from the vagina when the bitch made some expulsive efforts. After several unsuccessful attempts to dislodge the large calculus I chloroformed the animal, dilated the 